\title{
Service planning and delivery outcomes of home adaptations for ageing in the UK
}

\author{
Wusi Zhou $^{1}$ (D) Adekunle Sabitu Oyegoke ${ }^{1} \cdot \operatorname{Ming}_{\operatorname{Sun}^{1}}$
}

Received: 9 November 2016/Accepted: 25 November 2017/Published online: 13 December 2017

(C) The Author(s) 2017. This article is an open access publication

\begin{abstract}
In response to the impact of demographic change on the healthcare system, 'ageing in place' was introduced as a national policy to support elderly people living independently in their homes. Housing adaptation is essential for successful independent living and has been given increased political priority. However, adaptation policies and practice vary regionally, reflecting statutory limits, policy choices and local planning. This study investigated the current status of adaptation provision in different regions in the UK and assessed the effectiveness of local service planning and management. A mixedmethods sequential explanatory research strategy was employed. In the first quantitative phase, a questionnaire survey was carried out involving all 378 local authorities in England, Scotland and Wales. This was followed by a second qualitative phase involving individual interviews with five professionals and two clients and a focus group meeting with six key stakeholders. The study found that the current number of adaptations was relatively small compared with potential demands in most local areas, as was funding for adaptations. On the operational side, the adaptation process was fragmented, involving different service groups in many local authorities. There were disconnections between these groups, which often caused inefficiencies and poor effectiveness. Moving forward, local authorities need to have a clear vision of the overall need for adaptations and allocate sufficient resources. Practical guidelines are also needed for better integrated working and performance management.
\end{abstract}

Keywords Housing adaptation $\cdot$ Ageing in place $\cdot$ Older people $\cdot$ Service planning · Partnership work

Wusi Zhou

wz78@hw.ac.uk

1 Centre of Excellence in Sustainable Building Design, School of Energy, Geoscience, Infrastructure and Society, Heriot-Watt University, Edinburgh EH14 4AS, UK 


\section{Introduction}

A common consequence of old age is the reduction of functional abilities, which in turn leads to the need for long-term care or hospital admissions (van Hoof et al. 2009). It has been estimated that $52 \%$ of people aged 65 or over had age-related impairment or disability and $40 \%$ of the National Health Service budget was spent on caring for this age group (Adams 2016). Indeed, this demographic trend has posed a significant challenge to the sustainability of the UK healthcare system. In response to this challenge, 'ageing in place', as an established concept, was embraced by the UK government. It underpins a new care approach that delivers services to support elderly people remaining at home rather than requiring them to move to hospitals or care homes (Burgess and Morrison 2016; Kempton and Gawin 2011). Central to this approach is the principle of independent living. To achieve maximum independence for elderly adults, three things are essential (Heywood et al. 2002): (1) the home needs to be in good conditions and not cause any physical or mental illness; (2) a service is available when required to help with housework; (3) adaptation is required that makes all the rooms accessible for older occupants. Within this context, housing adaptations are vital vehicles not only for moving to a broader choice of independent living arrangements (Fänge and Iwarsson 2005; Renaut et al. 2015), but also for guaranteeing an effective usage of public resources (e.g. Chiatti and Iwarsson 2014; Heywood and Turner 2007; Howard-Wilsher et al. 2016).

Housing adaptation has been used interchangeably with 'home modification' and defined in many different ways. Some literature used the term to describe a rearrangement of furniture or fittings (e.g. removal of carpet) and a provision of equipment or devices (e.g. shower chair, movement sensors) (Pynoos et al. 2003; Sanford 2012); others explained it as an alternation to the physical environment (e.g. replacement of a bath, installation of a ramp) that enables an individual with a functional limitation to perform everyday activities at home (Johansson et al. 2007; Petersson et al. 2009). In this study, housing adaptation refers to modifications of permanent physical features in the indoor and immediate outdoor environment to reduce environmental barriers and restore independent living.

In the UK, local authorities have the statutory duty to provide grants for housing adaptation that is assessed necessary to improve the accessibility of the property and help people with disabilities remain in their own homes (Sakellariou 2015). In principle, adaptation grants are available to all disabled persons, but elderly people have been the main users of adaptation services (Department for Communities and Local Government [DCLG] 2009). The application process for housing adaptation usually starts when a need becomes known to the welfare authority (e.g. social services in England and Wales, social work in Scotland) through a process known as 'referral'. Often referrals take the form of requests for adaptation services from the healthcare professionals. On receipt of a referral, a case is allocated to specific fieldworkers, mainly occupational therapists (OTs), for assessment. OTs decide whether an assessed need matches the funding eligibility criteria; they also specify the types of adaptations required. The case is then passed to the grant officers for funding approval. If the client is a tenant, it is necessary to obtain landlord permission before any adaptation is carried out. Once plans and specifications for the adaptation work are confirmed, contractors are invited to submit quotations for the installation of the adaptation work. A contractor will be selected by the client to carry out the work and will then invoice the local authority after the completion of the adaptation work.

Previous studies have found that adapting the home environment to support people ageing in place could improve an individual's independence, health and quality of life (e.g. 
Heywood 2004; Hwang et al. 2011; Pettersson, et al. 2012), reduce strain on carers and restore family relationships (Heywood 2005; Tanner et al. 2008), shift care from the hospital to community and create healthcare spending savings (Adams 2008; Pleace 2011). These potential benefits are also acknowledged in various national policy documents, such as 'Strategy for Older People in Wales', 'Opportunity Age in England' and 'All Our Futures in Scotland'. However, so far there is no legislation or guidance that identifies one primary organisation responsible for the delivery of adaptations. Instead, different local authorities are allowed to decide on their own guidelines, procedures and eligibility criteria. Consequently, the current adaptation implementation is fragmented and sometimes confusing. There is an urgent need for reviewing the current practice in different parts of the UK and assessing the effectiveness of service planning and delivery. This study aimed to fill this gap by conducting a survey involving all the local authorities in England, Scotland and Wales, seeking to address the central research question: how do local authorities plan and manage housing adaptation services and to what extent have local authorities implemented the ambitions of national strategies and policies on 'ageing in place'.

\section{Legal framework for housing adaptations}

Under devolution settlements in 1998, a range of responsibilities for matters related to health, social care and housing were transferred to the Scottish Parliament and the Welsh Assembly (e.g. McCormick et al. 2009; Mitchell 2011; Trench and Jeffery 2007). Scotland constitutes a separate legal jurisdiction, while Wales shares the unified justice system with England (Stevenson and Huws 2014). There are differences in the types of financial assistance for housing adaptation in different countries, but they share the same principle of housing tenure determining the types of help available. In England and Wales, people in all tenures, owner occupiers or tenants of rented properties, may apply for disabled facilities grants (DFGs) for housing adaptations. However, in practice the local housing authorities and housing association are encouraged to undertake adaptations for their tenants using their own budgets (e.g. housing revenue account, housing association funding) instead of DFGs. Policies in Scotland follow similar lines. Home owners or private tenants receive grants for adaptations through the Scheme of Assistance, while public sector tenants apply for alternative funding from their landlords. These tenure-driven mechanisms are the legacy of imprecise legislation, which resulted in fragmented responsibilities between different departments and organisations. Therefore, although there are various funding routes in different countries, the legal principle behind them is broadly similar across the UK; the following discussion takes English law as an example.

In England, the legislative framework that sets out the powers and duties of local authorities to provide adaptations consists of five pieces of legislation (Table 1). While local social services departments have general duties under the CSDP Act to fund adaptations, the housing authorities usually assist with adaptations through housing grants (mainly DFGs) under housing legislation and have become the major provider of adaptation services. In addition to DFGs, another two specific grants, housing revenue and housing association funding, are often used by local authorities and housing associations to fund adaptations in their own properties. Therefore, the funding avenues available depend on the types of tenure, as shown in Table 2. 
Table 1 Legislation on the provision of adaptations

\begin{tabular}{|c|c|c|}
\hline Legislation & Gives powers to & Duties \\
\hline National Assistance Act 1948 & $\begin{array}{l}\text { Social service } \\
\text { department }\end{array}$ & $\begin{array}{l}\text { Provide assistance for promoting the welfare of } \\
\text { disabled people }\end{array}$ \\
\hline $\begin{array}{l}\text { Chronically Sick and Disabled } \\
\text { Persons Act } 1970 \text { (CSDP Act) }\end{array}$ & $\begin{array}{c}\text { Social service } \\
\text { department }\end{array}$ & $\begin{array}{l}\text { Identify the numbers and needs of disabled } \\
\text { people } \\
\text { Provide housing services including any works of } \\
\text { adaptations }\end{array}$ \\
\hline Housing Act 1974 & Housing department & $\begin{array}{l}\text { Bring additional financial assistance to support } \\
\text { adaptation services: } \\
\text { 1. Improvement grant } \\
\text { 2. Intermediate grant (mandatory) } \\
\text { 3. Special grant } \\
\text { 4. Repairs grant }\end{array}$ \\
\hline $\begin{array}{l}\text { Local Government and Housing } \\
\text { Act } 1989 \text { (LGH Act) }\end{array}$ & Housing department & $\begin{array}{l}\text { Abolish all above grants and introduce new } \\
\text { housing grants: } \\
\text { 1. Renovation grant (mandatory) } \\
\text { 2. Common parts grant } \\
\text { 3. Disabled facilities grant (DFG) (mandatory, } \\
\text { the level of grant is up to } £ 20,000 \text { and subject } \\
\text { to a test of resources) } \\
\text { 4. HMO grant } \\
\text { 5. Minor works assistance } \\
\text { Set up home improvement agencies to help older } \\
\text { people }\end{array}$ \\
\hline $\begin{array}{l}\text { Housing Grant, Construction } \\
\text { and Regeneration Act } 1996 \\
\text { (HGCR Act) }\end{array}$ & $\begin{array}{l}\text { Social service } \\
\text { department } \\
\text { housing } \\
\text { department }\end{array}$ & $\begin{array}{l}\text { Replace the above } 1,2,4 \text { grants with } \\
\text { discretionary grant } \\
\text { Retain mandatory DFG with some changes (e.g. } \\
\text { a maximum of } £ 30,000 \text { and the test of } \\
\text { resources only applies to the applicant and } \\
\text { partner) } \\
\text { Rename minor works assistance with home } \\
\text { repairs assistance }\end{array}$ \\
\hline
\end{tabular}

Table 2 Funding avenues for adaptations in different tenures (England as example)

\begin{tabular}{lllll}
\hline & $\begin{array}{l}\text { Owner } \\
\text { occupiers }\end{array}$ & $\begin{array}{l}\text { Private } \\
\text { tenants }\end{array}$ & $\begin{array}{l}\text { Council } \\
\text { tenants }\end{array}$ & $\begin{array}{l}\text { Housing association } \\
\text { tenants }\end{array}$ \\
\hline Disable facilities grants & $\boldsymbol{V}$ & $\boldsymbol{\checkmark}$ & $\boldsymbol{\checkmark}$ \\
Home repair assistance & $\boldsymbol{V}$ & $\times$ & $\boldsymbol{V}$ & $\times$ \\
Social services budgets & $\boldsymbol{V}$ & $\times$ & $\times$ & $\boldsymbol{V}$ \\
$\begin{array}{l}\text { Housing revenue or other } \\
\text { resources }\end{array}$ & $\times$ & $\times$ & &
\end{tabular}


According to the LGH Act (section 114) and the HGCR Act (section 24), for approval of a DFG, the housing authority should satisfy that an adaptation is necessary and appropriate for the needs of a disabled applicant and it is reasonable and practicable to adapt the property. In deciding whether the adaptation work is necessary and appropriate, the housing department should consult the social services department. Therefore, the adaptation process normally involves at least two local departments within the unitary authority - the social services department for assessment and the housing department for grant approval. In a two-tier system, decision making usually involves two different levels of authorities, where the county council provides Occupational Therapist assessment and the district council awards grants. Since the introduction of Home Improvement Agencies (HIAs) in the LGH Act, many local authorities have worked in partnership with HIAs who offered help from discussing the client's needs to supervising the building work during the delivery of DFGs. Because of the complicated web of legislation, it is quite common to find that the adaptation process is administered by multiple departments and organisations in many local authorities (Heywood 1994; Ramsay 2010). As a result, clients, many are elderly people, have to deal with a variety of organisations and professionals when carrying out home adaptations. The feature of tenure-based funding and multi-agency involvement is shared internationally, although different countries organise adaptation services differently (Johansson et al. 2009; Pynoos et al. 1998). For example, in the United States, a range of public funding options are available for home adaptations and each has its own eligibility criteria like housing tenures (Pynoos et al. 2003). A Swedish study also showed that disabled people need to engage with a number of professionals such as doctors, OTs and craftsmen in their navigation through the adaptation system (Johansson et al. 2010).

\section{Deficiencies of current adaptations practice}

After recognising the importance of housing adaptations in facilitating ageing in place, the UK government has injected extra funding into this area on an annual basis (Adams and Ellison 2009). In England, the total allocation for DFGs was more than tripled from $£ 56$ million in $1997 / 1998$ to $£ 185$ million in $2013 / 2014$ (Wilson 2013) and other funding sources (e.g. social services grants, HRA) also made generous contributions to adaptation services (Heywood and Mackintosh 2008; Wane 2016). Evidence of adaptations already taken place seems encouraging. However, there were still substantial unmet needs (DCLG 2011; Scottish Government 2010). In fact, many local authorities were unaware of the extent of unmet needs for adaptations (Fenton and Markkanen 2009; Heywood et al. 2005). Identifying the real need is crucial for securing appropriate resources and establishing effective supports (Brewis 1997).

The common causes of unmet needs have been explored in previous research (e.g. Clayton and Silke 2010; Keeble 1979; Kersten et al. 2000). Insufficient funds appear to be a dominant factor (e.g. Appleton and Leather 1997; Audit Commission 2002; Perry 2015). According to the English housing condition survey (DCLG 2011), funding required to cover all eligible adaptations was $£ 1.9$ billion in 2005 , which represented over ten times the total allocation for DFGs in 2013/2014. The demand has been accelerating with ageing of the population and far exceeded the available funds (Jones 2005; Heywood et al. 2005). As a result, some old applicants had to wait for years to receive their required adaptations and enjoyed little time to benefit from the adaptation work (Higham 1999; Mackintosh 2012). The funding shortage problem was often exacerbated by conflicts between partner 
organisations involved in the process of adaptations (Foundations 2008; Home Adaptations Consortium [HAC] 2013). As there is no national policy or guidance that specifies service responsibility and coverage between partner agencies, the structures for inter-agency collaboration have always been poor or ineffective. As a result, it led to misuse of resources and inequity of service provision (Hall and Scottish Executive 2001; Adaptation Working Group [AWG] 2012).

There are also issues with budget management and performance monitoring, which prevent local authorities from getting the best value out of the existing adaptation investments. A survey on adaptation spending halfway through the financial year showed that around $25 \%$ of local authorities used up their whole year funding allocations; another $31 \%$ already overspent by a big margin, and only $43 \%$ kept their expenditure within budget limits (Ramsay 2010). Authorities, who had difficulties in managing their budgets, tended to defer requests, resulting in a great number of people with unmet needs (Heywood et al. 2005). Furthermore, monitoring the outcomes of housing adaptations became indispensable to service quality and improvement (HAC, 2013). Unfortunately, there was no consistent way to measure service performance across local authorities and the inconsistency frequently interfered with strategic planning for future adaptation delivery (Bibbings et al. 2015).

\section{Methods}

\subsection{Study design}

The goal of this study is to examine the effectiveness of the current service planning and delivery of housing adaptations in the UK. It chooses to focus on homeowners and private tenants instead of local authority or housing association tenants. The reason for this choice is twofold. First, homeowner occupiers and private tenants account for the majority of households in the UK. Second, most of them have little knowledge about where to start and what assistances are available when they need adaptations. A mixed-methods sequential explanatory research strategy was employed. In the first quantitative phase, a questionnaire survey was conducted to investigate how local authorities plan, organise and monitor their adaptation services. The second qualitative phase included seven interviews and one focus group with stakeholders, including social worker, occupational therapists, housing officers, staff from care and repair $(C \& R)$ and older clients; the aim was to explore the statistical results in depth from different perspectives. In such a research design, the quantitative results inform the qualitative data collection and the qualitative analysis offers in depth explanations for issues identified in the quantitative phase (Creswell 2013; Greene et al. 1989). The rationale for this design is that neither the quantitative nor qualitative method in itself is sufficient to obtain a deep understanding of the research question, but with their combination they can complement each other for a more comprehensive analysis (Ivankova et al. 2006; Schwingel et al. 2017).

Considering the main aim of this study, priority was given to the quantitative method, as it provides the main evidence on the current status and the factors that affected the service planning, process and management in different local authorities. The lesser qualitative component was targeted at capturing experiences and views of stakeholder representatives on key issues identified by the quantitative results. The findings of both research methods were combined in the discussion sections. 


\subsection{Data collection}

The study started with a review of policy documents, research reports and journal papers, which revealed considerable variations amongst local authorities in resource allocation, budget management and delivery outcomes. A postal questionnaire survey (McColl et al. 2001) was then carried out, targeting all local authorities across Great Britain except the county councils in England, who did not fund adaptations directly and only provided assessment. Northern Ireland was excluded as it has a unique Health and Social Services under a unified structure, which is different from other nations in the UK (Boniface et al. 2013). The survey covered questions on service planning, joint work, the application process and performance monitoring. Prior to the main survey, a pilot study was done with 20 local councils. As a result of the pilot, modifications were made to some questions. The finalised questionnaire was posted to all local councils, along with a cover letter and postage prepaid envelope, in England (324), Scotland (32) and Wales (22). It was sent to the housing departments of these local authorities with a response deadline of 2 weeks. The questionnaire was also made available online for those who preferred to reply online. Reminder phone calls were made to non-respondents after 4 weeks, followed by email reminders. At the end of this process, a total of 112 local authorities responded to the survey, with 61 completed questionnaires returned by stamped envelopes, 28 responses received from online, and another 23 sent back by emails. The response rate was $29.6 \%$, which is comparable to other studies, such as Connell et al. (2009) and Davies et al. (2012). It is difficult to generalise the reasons for all non-respondents, apart from the usual apathy of practitioners towards academic research. A post-survey analysis showed that those who did not reply shared characteristics of operating tenure-based funding systems and separating the process into different stages that involved different organisations.

Following the questionnaire survey, interviews (Berg et al. 2004) and a focus group (Gill et al. 2008) were carried out. The interviews were explanatory, designed to gain a more comprehensive picture of current adaptation provision from the perspectives of different stakeholders, including service providers and older clients. Five professional participants were interviewed; they worked in different departments or organisations responsible for different stages and were experienced in the adaptation system. These professionals were interviewed in their offices; each interview lasted between 60 and $150 \mathrm{~min}$. The interview questions were open-ended, focusing on service planning, organisation and management. Two clients were identified during the interviews with staff from the service provider-C\&R. They provided a service user perspective for the existing delivery system, based on their personal experience. The selected interviewees were elderly adults (aged 65 or over) with disabilities and had received a housing adaptation grant in the last 2 years. Interviews with them were conducted in their homes for around $60 \mathrm{~min}$ and included questions about their expectations, concerns and experiences of having an adaptation carried out. These interviews gave valuable insight into the difficulties of accessing adaptation service information provided by local authorities. A focus group was organised in one local council to gain a deep understanding of key issues with financial and administrative arrangements on housing adaptations. This council was chosen because it has social work, the housing department and C\&R working in partnership to carry out adaptations and it was accessible to the researcher. Participants in the focus group included one OT, two housing officers (one senior, one junior), one technical officer, one $\mathrm{C} \& \mathrm{R}$ manager and one coordinator. The selection criteria were based on long-term working partnership in a team and having attended regular meetings for the delivery of 
adaptations within the authority for more than 2 years. All interviews and focus group discussion were recorded and transcribed verbatim afterwards.

\subsection{Data analysis}

The data were analysed in accordance with the specific procedures in the mixed methods sequential explanatory design (Creswell 2013). First, quantitative data were analysed by using the Statistical Package for the Social Science (SPSS 22, Inc., Chicago, IL 2013). The frequencies in Table 4 display the percentage of local authorities who answered 'yes' to different questions and measured the central tendency to summarise the common practices in organising adaptations from planning to completion. Correlation and regression analysis (Rioux and Werner 2011) examined relationships between variables to identify key factors that impacted the effectiveness of adaptation services. Second, data from the interviews and focus group were analysed using NVivo 10 (QSR International, Melbourne, Australia 2012) and coding was generated to seek core categories and themes (Ivankova et al. 2006). The emerging themes were reinvestigated and divided into subthemes (Table 3 ).

\section{Results}

Table 4 shows survey results in relation to budget planning, budget monitoring, partnership work and performance management. Seventy-one of 112 local authorities currently operate different systems of adaptation funding for different tenures and $94.6 \%$ of them do not have a plan to pool the different funding sources together for all tenures. When setting the annual budget, $78.4 \%$ of local authorities relied on the previous year's spending and only $14.4 \%$ carried out surveys of need. Only 38 local authorities increased budgets for housing adaptations in the year 2014/2015. The rest kept the same funding allocation; some even trimmed their budget. Despite this, $71.2 \%$ of respondents claimed that their

Table 3 Themes and subthemes
Theme 1: Budget planning and monitoring

Subthemes

Different funding streams

The way of setting the budget

The real need for adaptations

Budget management

Theme 2: Partnership work

Subthemes

The role of HIA/C\&R

Links between partner organisations

Features of cooperation

Better information sharing

Theme 3: Performance management

Subthemes

The monitoring system

A standardised approach

Performance indicators 
Table 4 Descriptive statistics of variables regarding planning, partnership and performance

Survey questions

Budget planning and monitoring

Have different funding for adaptations in different tenures

Have plan to pool different funding streams into a single pot

Ways to set budget targets for adaptations (multiple responses)

Survey of needs

Review of the last year's spending

Consultation with relevant organisations

Other (e.g. waiting lists, available resources)

Has this year's budget changed compared with the last year

Increased

Decreased

Stayed the same

Budget allocation is sufficient to meet the demand

Monitor actual expenditure against budget

Monthly

Quarterly

Half-yearly

First come first served basis

Other (e.g. weekly, yearly)

Partnership work

Partners involved in the adaptation process (multiple responses)

Housing department

Integration authority

Social services

Associated organisations (e.g. HIA, C\&R)

Other (e.g. NHS, adult care)

Have written guidance on service entitlement between partners

Effectiveness of current partnership

Very ineffective

Fairly ineffective

Fairly effective

Very effective

Performance management

Have collected information to monitor performance

Performance indicators include

Positive outcomes

Customer satisfaction

Impact of adaptations

40.2

Delivery times

Other (e.g. C\&R returns, contractor activities) 
budget allocation was sufficient to meet demand. Ninety-one local authorities monitored spending against the budget on a monthly basis. In most local authorities, the housing department, social services department and associated agencies, such as HIA and C\&R, were the key partners in delivering housing adaptations. Eighty-seven councils have laid down guidelines to specify service entitlement and service process between partner organisations; $91.7 \%$ of respondents considered the current joint working as fairly effective or very effective. Ninety-nine local authorities collected performance information to monitor the achievement of adaptation services. Performance indicators mainly included positive outcomes, customer satisfaction and impacts of adaptations.

Table 5 presents the headline statistics of delivery outcomes, including minimum, maximum and average numbers of adaptations and funding at the local authority level in the three nations of the UK. The numbers indicate considerable variations amongst local authorities in both the number of approved adaptations and the amount of allocated funding. The UK average number of adaptations completed in 2014/2015 was 154 and an average value of $£ 5046$ per adaptation for all the councils. The average number of adaptations was 279 in Wales and average cost was £7902. In comparison, the average number was 129 adaptations in England and 269 in Scotland; the average cost per adaptation was $£ 5610$ in England and $£ 1782$ in Scotland. Further analysis of different aspects of the adaptation process is presented in following sections.

\section{Analysis and discussion}

\subsection{Budget planning and monitoring}

Budget planning is the starting point for providing housing adaptations. It mainly involves two elements: first, identifying the potential need for adaptations and then allocating the necessary resources to meet the need. Because of various grant schemes that affect the funding of adaptations in different tenures, AWG (2012) and Heywood et al. (2005) recommended a single funding pot that covers all adaptation financing sources for all types of housing tenure. However, the survey showed that this proposal had not been widely adopted and multiple budget sources for different housing tenures still prevailed in $63.4 \%$ of local councils. During the interview, a social worker described the current status:

We do not have a pooled budget but have a line budget. We got house revenue for council properties, a block grant for the private sector and equipment budget. The

Table 5 Number of approved adaptations and amount of allocated funding 2014/2015

\begin{tabular}{llllll}
\hline & Countries & Minimum & Maximum & Mean & SD \\
\hline Number & England & 29 & 976 & 129 & 138 \\
& Scotland & 20 & 1545 & 269 & 404 \\
& Wales & 100 & 500 & 279 & 172 \\
Cost & England & $£ 130,000$ & $£ 4,013,000$ & $£ 723,650$ & $£ 597,316$ \\
& Scotland & $£ 125,494$ & $£ 1,852,131$ & $£ 687,544$ & $£ 479,303$ \\
& Wales & $£ 850,000$ & $£ 4,500,000$ & $£ 2,212,500$ & $£ 1,669,518$ \\
\hline
\end{tabular}


only budget we do not have is the housing association budget; the housing association budget sits within the individual housing association.

Many reasons have been suggested for keeping the multiple funding streams arrangement, such as reducing budgets for private sector housing and avoiding running out of budget mid-year. A recent report on adaptation services in Wales further highlighted that closing down funding streams and moving into a unified system would result in higher costs but not better outcomes (Bibbings et al. 2015). Likewise, this survey did not find significant correlations among a single funding pot, delivery outcomes and service effectiveness. Therefore, it is essential to balance the value of a tenure neutral system with the difficulties of aligning multiple adaptation funds.

Nevertheless, the central government seeks for greater integration between health and social care and puts all relevant resources together in a single pooled budget (Ham and Walsh 2013; Mandelstam 2016; Wilson 2013). As a result, the adaptation grants are going to be swallowed up by this single pot. For example, the Better Care Fund was announced in England to pool resources across housing, health and social care boundaries and DFG became an element of the Better Care Fund. This policy initiative has ignited an intense debate about the future funding for adaptations. Some professionals welcomed this movement and believed that the integrated fund could provide more home adaptations. An interviewed social worker said:

Because of financial cuts in public services, placing adaptation services within a broader policy context would help more elderly people to remain independent in their own homes.

However, there were certain concerns about the uncertainty of future government funding for adaptations through Better Care Fund, leading to a great challenge for service planning, as explained by a housing officer:

Budget allocation now comes from the county council via the better care fund; it is not known what this budget will be for next year, which makes planning difficult. It would be useful if this were set in advance.

Because of an ageing population, local authorities found it hard to make predictions about budgets for housing adaptations, as noted by a grant officer:

Budget is extremely difficult to predict; so is the number of adaptations required as demographic changes taking place.

This survey revealed that the majority of local authorities (78.4\%) set the adaptation budget based on the previous year's spending, as highlighted by a social worker:

For forward planning, what we do is trend analysis. We look at the number of completed adaptations, look at the bound budget, add a certain percentage of cost for extra requests for adaptations and then project what is required for the next year.

During the interview, a housing officer criticised this budget setting approach for even failing to account for the accurate spending:

Levels of expenditure in any 1 year will not match levels of approval because of the time lag between approval and payment on completion of works. This can be as much as 12 months' differences. 
Carrying out surveys was considered the best way to identify the potential need (Heywood 1994; HAC 2013), but only a few councils (14.4\%) have conducted such surveys. More worryingly, $15.3 \%$ of local authorities did not adopt any formal budget-setting methods; resources for housing adaptations depended entirely on the annual funding allocation from the central government.

The survey found that $50 \%$ of local authorities maintained the same budget in the coming year after reviewing the previous year's spending; $14.2 \%$ of them even reduced their budget. This contradicts the expected increase in demand for adaptation as the ageing population increases. National housing surveys revealed that the volume of demand for adaptations remained far beyond the current supply (Adams and Ellison 2009; Scottish Government 2010). Table 6 illustrates the correlation between the current adaptation budget allocations and budget change. Most of local authorities allocated total funding between $£ 250,000$ and $£ 750,000$ and only $19.6 \%$ of authorities spent over $£ 1,000,000$. Those that reported a budget increase spent more on adaptations with a mean budget of $£ 652,688$. In comparison, the mean budgets were $£ 566,736$ and $£ 541,820$ for the 'budget decreased' and 'stay the same' groups, respectively.

According to the survey, $71.2 \%$ of local authorities claimed that their budget allocation was sufficient to meet the demand. However, Table 5 explains that the number of average adaptations carried out by each local authority is relatively small. Table 7 shows no clear link between the supply and demand. Local authorities, which claimed to have sufficient funding, actually carried out fewer adaptations than those claiming insufficient funding. One inference from this could be that the depressed demand for adaptation appeared to be met in some local authorities only because such a service was not widely known. This was confirmed in interviews with a technical officer and an elderly client:

Adaptations are demand led and due to limited resources; the availability of grants is not widely published or promoted. This could potentially mean there are people in need who are unaware of this service to help them.

I didn't know the grant until I went to the Care \& Repair and many of my friends never heard of it.

Table 6 Relationship between the budget change and total amount

\begin{tabular}{lllll}
\hline & $\begin{array}{l}\text { All } \\
(n=102)\end{array}$ & $\begin{array}{l}\text { Budget increased } \\
(n=36)\end{array}$ & $\begin{array}{l}\text { Budget decreased } \\
(n=14)\end{array}$ & $\begin{array}{l}\text { Stay the same } \\
(n=50)\end{array}$ \\
\hline $\begin{array}{l}\text { Total allocated funding }(£) \\
\text { Less than }\end{array}$ & $8.8 \%$ & $8.3 \%$ & $0.0 \%$ & $12.0 \%$ \\
$250 \mathrm{k}$ & & & \\
$250-500 \mathrm{k}$ & $33.3 \%$ & $25.0 \%$ & $50.0 \%$ & $32.0 \%$ \\
$500-750 \mathrm{k}$ & $25.5 \%$ & $30.6 \%$ & $14.3 \%$ & $26.0 \%$ \\
$750-1000 \mathrm{~K}$ & $12.8 \%$ & $13.9 \%$ & $21.4 \%$ & $10.0 \%$ \\
$\begin{array}{l}\text { Over 1000 K } \\
\text { Median }\end{array}$ & $19.6 \%$ & $22.2 \%$ & $14.3 \%$ & $20.0 \%$ \\
number & 566,960 & 652,688 & 566,763 & 541,820 \\
\hline
\end{tabular}


Table 7 Relationship between supply and demand

\begin{tabular}{lccc}
\hline & All $(n=102)$ & Demand met $(n=75)$ & Demand not met $(n=26)$ \\
\hline Number of approvals $(n)$ & & & \\
Less than 50 & $17.6 \%$ & $21.3 \%$ & $7.7 \%$ \\
$51-100$ & $30.4 \%$ & $29.4 \%$ & $34.6 \%$ \\
$101-150$ & $23.6 \%$ & $25.3 \%$ & $15.4 \%$ \\
$151-200$ & $12.7 \%$ & $12.0 \%$ & $15.4 \%$ \\
Over 200 & $15.7 \%$ & $12.0 \%$ & $26.9 \%$ \\
Median number & 105.5 & 100.0 & 123.5 \\
\hline
\end{tabular}

Previous research has suggested that political pressure might deter local authorities to advertise adaptation services widely (Appleton and Leather 1997; Scott et al. 2009). As the population is ageing, the dissemination of grants information will push up the demand for adaptations, which in turn will pressurise councils to increase available resources.

In fact, the shortage of finance was reported by some local authorities. A social worker commented:

The equipment and adaptation regularly over spend the budget quite a lot; we spent budget more than we have; we have budget difficulty; we have debates for many years.

When there was not enough funding to meet the demand, delays often occurred and the waiting lists built up:

Demand for adaptations exceeds financial resources, which means a waiting list for DFGs (a housing officer).

There were frequent references to the difficulty of keeping expenditures within the budget limits, although $81.3 \%$ of local authorities monitored spending against the budget on a monthly basis. Such difficulty means that extra sources of funding are needed. When a large increase of funding is impossible, local authorities have to balance between available resources and waiting lists for adaptation.

\subsection{Partnership work}

Under the current legislation, social services departments are responsible for providing needs assessment and housing departments for grants approval. Unsurprisingly, the survey found that the two departments were the key partners for the delivery of adaptations. Other associated organisations such as HIAs and C\&R also played an important role in carrying out adaptations. Many local authorities worked with them to improve process efficiency and service quality, as commented by an occupational therapist:

We already have an effective working partnership and discuss any issues regularly and in a more formal process at the care and repair advisory group meetings.

Those who had not entered into partnership expected their arrival to achieve better performance, as recognised by a housing officer: 
It would be beneficial to have one dedicated agency in our location as this would minimise delays, misunderstandings of policies and procedures and create best practice.

It was quite common to find that three or more organisations worked together to deliver an adaptation job. Strong links among these organisations are the key for effective service delivery, as recommended by previous studies (Heywood 1994; Lawler 2015; Donald 2009). An interviewed occupational therapist explained:

We do a lot of work with statutory partners and also forge links with associated organisations to deliver a package of work rather than asking the client to engage each agency individually, which is a great cost saving and delivers a much better service.

There have been many improvements in partnership working and $90.7 \%$ of the survey respondents considered their current partnership arrangement as 'fair effective' or 'very effective'. A service provider representative, a Care and Repair manager, commented:

Our partnership works really well and several steps have already been taken to reduce waiting time, e.g. the introduction of contractor framework.

However, there were still complaints about disconnections between partners particularly when they spread over more than one local authority. One housing officer complained:

OT in the county council has to shut their case down once it is passed to the district council. If the case has any question or changes, we have to request to reopen the case again in the county council. It takes time as it could be a different OT to deal with the case.

Solutions for better information sharing between the partners were recognised as important for effective partnership, as commented by a housing officer:

Shared IT procurement of adaptation systems between OT and housing officers would help speed up the process.

The survey found that a clear guidance for cooperation had a positive impact on effective joint work (Table 8). Of 85 councils who have published guidance on joint work for delivering adaptations, $44.7 \%$ of them described their partnership as 'very effective', while in the remaining 22 councils who did not have written procedures, only $13.6 \%$ gave the same answer.

Table 8 Crosstabs between guidance and partnership effectiveness

\begin{tabular}{|c|c|c|c|c|c|}
\hline & \multicolumn{5}{|c|}{ Effectiveness of partnership } \\
\hline & Very ineffective & Fairly ineffective & Fairly effective & Very effective & Total $(n / \%)$ \\
\hline \multicolumn{6}{|c|}{ Cooperation guidance } \\
\hline \multirow[t]{2}{*}{ Yes } & 5 & 1 & 41 & 38 & 85 \\
\hline & $5.9 \%$ & $1.2 \%$ & $48.2 \%$ & $44.7 \%$ & $100 \%$ \\
\hline \multirow[t]{2}{*}{ No } & 0 & 3 & 16 & 3 & 22 \\
\hline & $0.0 \%$ & $13.6 \%$ & $72.7 \%$ & $13.6 \%$ & $100 \%$ \\
\hline
\end{tabular}




\subsection{Performance management}

To demonstrate value for money, measurements need to be put in place to evaluate the effectiveness of housing adaptations (Awang 2002; HAC 2013). This was generally agreed on by all local authorities; $90 \%$ of them collected certain information to monitor the achievement of adaptations and report service performance. Such information was believed to be helpful for sharing good practice and improving service delivery. One housing officer said:

Consideration of service standards for each area and more opportunity to reflect on performance may highlight areas to address and allow improvement in speed of delivery.

Unfortunately, a small number of local authorities did not adopt any performance monitoring. A housing officer from another area said that:

We used to collect performance indicators to monitor the adaptation process but now stopped when the staff levels out.

This situation was more common when there was no guidance that specified the service coverage and service process between partner organisations. As shown in Table 9, over $94 \%$ of local councils who have agreed guidance on partnership working collected performance indicators to monitor the adaptation process compared with less than $74 \%$ of those who did not have a partnership agreement. This result again emphasised the importance of guidance in the provision of adaptations.

Although performance monitoring systems were in common use, the way in which performance information was gathered varied greatly, with some authorities using a single performance indicator and others adopting a set of performance indicators. Some professionals suggested the establishment of a standardised system and more consistency in performance indicators, as explained by a housing officer:

Councils monitor adaptation performance in many different ways and should work towards standardising processes according to best practice.

A consistent approach to performance indicator collection can secure equity and efficiency in adaptation interventions; the same interviewee went on:

Working countrywide to create consistency in service recording and monitoring mechanisms could improve effectiveness of services.

The majority of local authorities (85.6\%) had reported positive outcomes of adaptations:

Table 9 Crosstabs between guidance and performance indicators

\begin{tabular}{lll}
\hline & \multicolumn{2}{l}{ Performance indicator collection for monitoring } \\
\cline { 2 - 3 } & Yes & No \\
\hline \multirow{2}{*}{ Cooperation } & guidance & \\
Yes & 80 & 5 \\
& $94.1 \%$ & $5.9 \%$ \\
No & 17 & 6 \\
& $73.9 \%$ & $26.1 \%$ \\
\hline
\end{tabular}


We mainly gathered the number of adaptations that we carried out and their cost over the year to monitor our performance as well as work out the forward planning (a social worker).

Of the local authorities, $77.3 \%$ also conducted post-service surveys to measure customer satisfaction levels:

We conduct the customer satisfaction survey to gather feedback on our service; our customer satisfactory levels have been at the highest levels $(96 \%, 99 \%)$ for many years (a staff from Care \& Repair).

\section{Conclusions}

Housing adaptations play a crucial role in supporting older people ageing in their own homes. National policies and strategies have made a commitment to take advantage of adaptation services. However, this study found that the average number of adaptations carried out each year in most local authorities is still relatively small compared with the potential demand from an ageing population. The level of government spending is also low; there is no sign of major changes in this regard. There are noticeable differences among the different nations in the UK. Overall, the Welsh government gave more attention to adaptation services and made them a higher political priority than England and Scotland, and it provided a higher level of funding. In Scotland, local authorities focus primarily on middle- and small-scale adaptations with a cost up to $£ 3000$. In England, the adaptation service is complex with the involvement of the two-tier government-the district and county councils.

Imprecise legislation and multiple grant schemes led to variations at the local authority level in funding for adaptation and its delivery process. The lack of a standard system makes it difficult for sharing best practice across different local authorities or benchmarking performance. Many local authorities set the housing adaptation budget mainly based on the previous year's spending instead of proper reviews of demand. This led to substantial unmet demand or hidden demand due to many elderly people simply not being aware of this service. Although most local authorities monitored actual expenditure against the budget monthly, overspending occurred frequently, causing adaptation waiting lists. The process of housing adaptation is currently administered by different groups in different local authorities and their joint working is the key for effective service delivery. Some local authorities suffer from ineffective service due to poor cooperation between different departments within the local authorities and partnering organisations. Performance management is widely adopted with the use of different monitoring methods and a variety of performance indicators. A standard framework in this regard will be useful in driving up the performance of housing adaptation service delivery across the whole county.

Acknowledgements The authors would like to thank Care and Repair Scotland and other research participants who shared their time and experiences.

\section{Compliance with ethical standards}

Conflict of interest The authors declared no potential conflicts of interest with respect to the research, authorship, and/or publication of this article. 
Open Access This article is distributed under the terms of the Creative Commons Attribution 4.0 International License (http://creativecommons.org/licenses/by/4.0/), which permits unrestricted use, distribution, and reproduction in any medium, provided you give appropriate credit to the original author(s) and the source, provide a link to the Creative Commons license, and indicate if changes were made.

\section{References}

Adams, S. (2008). What role for housing in health and social care provision? Journal of Integrated Care, $16(5), 30-36$.

Adams, S. (2016). Off the radar: Housing disrepair \& health impact in later life. Nottingham: Care \& Repair England.

Adams, S., \& Ellison, M. (2009). Home adaptations for older people: The increase in need and future of state provision. Nottingham: Care \& Repair England.

Adaptation Working Group. (2012). Adapting for change. Edinburgh: Scottish Government.

Appleton, N., \& Leather, P. (1997). Review of the provision of equipment \& adaptations for older people. London: King's Fund Publishing.

Awang, D. (2002). Older people and participation within disabled facilities grant processes. British Journal of Occupational Therapy, 65(6), 261-268.

Berg, B. L., Lune, H., \& Lune, H. (2004). Qualitative research methods for the social sciences. Boston, MA: Pearson.

Bibbings, J., Boniface, G., Campbell, J., Findlay, G., Reeves-McAll, E., Zhang, M., et al. (2015). A review of independent living adaptations. Cardiff: Welsh Government.

Boniface, G., Mason, M., Macintyre, J., Synan, C., \& Riley, J. (2013). The effectiveness of local authority social services' occupational therapy for older people in Great Britain: A critical literature review. British Journal of Occupational Therapy, 76(12), 538-547.

Brewis, C. (1997). Targeting the resources of housing adaptations for people with disabilities. The British Journal of Occupational Therapy, 60(3), 123-128.

Burgess, G., \& Morrison, N. (2016). Improving housing outcomes: The value of advice and support for vulnerable older people. Journal of Housing and the Built Environment, 31(2), 197-211.

Chiatti, C., \& Iwarsson, S. (2014). Evaluation of housing adaptation interventions: Integrating the economic perspective into occupational therapy practice. Scandinavian Journal of Occupational Therapy, 21(5), 323-333.

Clayton, V., \& Silke, D. (2010). Evaluation of the housing adaptation grant schemes for older people and people with a disability. Dublin: Housing Agency.

Commission, Audit. (2002). Fully equipped, 2002: Assisting independence: Audit Commission briefing. Edinburgh: Audit Commission.

Connell, J., Page, S. J., \& Bentley, T. (2009). Towards sustainable tourism planning in New Zealand: Monitoring local government planning under the Resource Management Act. Tourism Management, 30(6), 867-877.

Creswell, J. W. (2013). Research design: Qualitative, quantitative, and mixed methods approaches. CA: Sage.

Davies, K., Bullock, M., Brandon, A., Wainman, K., Craig, L., Fletcher, P., et al. (2012). A study of the housing and support needs of older people in Herefordshire. Northumberland: Peter Fletcher Associates Ltd.

Department for Communities and Local Government. (2009). Survey of English Housing, 2007-2008. London: DCLG Publications.

Department for Communities and Local Government. (2011). Disabled facilities grant allocation methodology and means test. London: DCLG Publications.

Donald, I. P. (2009). Housing and health care for older people. Age and Ageing, 38(4), 364-367.

Fänge, A., \& Iwarsson, S. (2005). Changes in ADL dependence and aspects of usability following housing adaptation-A longitudinal perspective. American Journal of Occupational Therapy, 59(3), 296-304.

Fenton, A., \& Markkanen S. (2009). Older people: Modelling housing need and demand and supply of potentially suitable housing, care and support services. Report to the Scottish Government.

Foundations. (2008). A review of demand for disabled facilities grant (DFG) in the east midlands. Midlands: Presented to Government Office East Midlands.

Gill, P., Stewart, K., Treasure, E., \& Chadwick, B. (2008). Methods of data collection in qualitative research: Interviews and focus groups. British Dental Journal, 204(6), 291-295.

Greene, J. C., Caracelli, V. J., \& Graham, W. F. (1989). Toward a conceptual framework for mixed-method evaluation designs. Educational Evaluation and Policy Analysis, 11(3), 255-274. 
Hall, E., \& Scottish Executive. (2001). Equipment and adaptation services in Scotland: A survey of waiting times for social work provision. Edinburgh: Scottish Executive Central Research Unit.

Ham, C., \& Walsh, N. (2013). Making integrated care happen at scale and pace. London: The King's Fund. Heywood, F. (1994). Adaptations-Finding ways to say yes. Bristol: SAUS.

Heywood, F. (2004). The health outcomes of housing adaptations. Disability \& Society, 19(2), 129-143.

Heywood, F. (2005). Adaptation: Altering the house to restore the home. Housing Studies, 20(4), 531-547.

Heywood, F., Gangoli, G., Langan, J., Marsh, A., Moyers, S., Smith, R., et al. (2005). Reviewing the disabled facilities grant programme. London: Office of the Deputy Prime Minister.

Heywood, F., \& Mackintosh, S. (2008). Housing associations and home adaptations: Making it work smoothly. London: Habinteg Housing Association Ltd.

Heywood, F., Oldman, J., \& Means, R. (2002). Housing and home in later life. Buckingham: McGraw Hill.

Heywood, F., \& Turner, L. (2007). Better outcomes, lower costs. Implications for health and social care budgets of investment in housing adaptations, improvements and equipment: Review of the evidence. London: Department of Work and Pensions.

Higham, E. (1999). Changing rooms: a survey of the adaptations service in six Welsh Authorities and the outcomes for service users with physical disabilities. Research Report to Wales Office of Research and Development in Health and Social Care.

Home Adaptations Consortium. (2013). Home adaptations for disabled people. Nottingham: Care \& Repair England.

Howard-Wilsher, S., Irvine, L., Fan, H., Shakespeare, T., Suhrcke, M., Horton, S., et al. (2016). Systematic overview of economic evaluations of health-related rehabilitation. Disability and Health Journal, 9(1), 11-25.

Hwang, E., Cummings, L., Sixsmith, A., \& Sixsmith, J. (2011). Impacts of home modifications on ageingin-place. Journal of Housing for the Elderly, 25(3), 246-257.

Ivankova, N. V., Creswell, J. W., \& Stick, S. L. (2006). Using mixed-methods sequential explanatory design: From theory to practice. Field Methods, 18(1), 3-20.

Johansson, K., Borell, L., \& Lilja, M. (2009). Older persons' navigation through the service system towards home modification resources. Scandinavian Journal of Occupational Therapy, 16(4), 227-237.

Johansson, K., Lilja, M., Park, M., \& Josephsson, S. (2010). Balancing the good-A critical discourse analysis of home modification services. Sociology of Health \& Illness, 32(4), 563-582.

Johansson, K., Lilja, M., Petersson, I., \& Borell, L. (2007). Performance of activities of daily living in a sample of applicants for home modification services. Scandinavian Journal of Occupational Therapy, 14(1), 44-53.

Jones, C. (2005). Review of housing adaptations including disabled facilities grants-Wales. Cardiff: Welsh Government.

Keeble, U. (1979). Aids and adaptations. London: Bedford Square Press.

Kempton, O., \& Gawin, A. (2011). Measuring the social return on investment of stage 3 adaptations and very sheltered housing in Scotland. London: Envoy Partnership Ltd.

Kersten, P., George, S., McLellan, L., Smith, J. A., \& Mullee, M. A. (2000). Met and unmet needs reported by severely disabled people in southern England. Disability and Rehabilitation, 22(16), 737-744.

Lawler, K. (2015). Ageing in place: Coordinating housing and healthcare provision for Americas growing elderly population. 2001. Washington, DC, Neighborworks.

Mackintosh, S. (2012). From home adaptations to accessible homes: Putting perople at the heart of redesigning the adaptation service in Bristol. London: Housing LIN.

Mandelstam, M. (2016). Home adaptations: The care act 2014 and related provision across the United Kingdom. London: College of Occupational Therapists Ltd.

McColl, E., Jacoby, A., Thomas, L., Soutter, J., Bamford, C., Steen, N., et al. (2001). Design and use of questionnaires: A review of best practice applicable to surveys of health service staff and patients. Health Technology Assessment, 5(31), 1-256.

McCormick, J., McDowell, E., \& Harris, A. (2009). Policies for peace of mind? Devolution and older age in the UK. London: Institute for Public Policy Research.

Mitchell, J. (2011). Devolution in the UK. Oxford: Oxford University Press.

NVivo qualitative data analysis software. (2012). NVivo qualitative data analysis software. QSR International Pty Ltd. Version 10.

Perry, F. C. (2015). Adaptation works: How disabled facilities grants are the overlooked solution to the accessible housing shortage and associated costs. England: Diability United.

Petersson, I., Kottorp, A., Bergström, J., \& Lilja, M. (2009). Longitudinal changes in everyday life after home modifications for people aging with disabilities. Scandinavian Journal of Occupational Therapy, 16(2), 78-87. 
Pettersson, C., Löfqvist, C., \& Malmgren Fänge, A. (2012). Clients' experiences of housing adaptations: A longitudinal mixed-methods study. Disability and Rehabilitation, 34(20), 1706-1715.

Pleace, N. (2011). The costs and benefits of preventative support services for older people. York: The Centre for Housing Policy, The University of York.

Pynoos, J., Nishita, C., \& Perelma, L. (2003). Advancements in the home modification field: A tribute to M. Powell Lawton. Journal of Housing for the Elderly, 17(1-2), 105-116.

Pynoos, J., Tabbarah, M., Angelelli, J., \& Demiere, M. (1998). Improving the delivery of home modifications. Technology and Disability, 8(1-2), 3-14.

Ramsay, M. (2010). Adapting for a lifetime: The key role of home improvement agencies in adaptations delivery. Derbyshire: Foundations.

Renaut, S., Ogg, J., Petite, S., \& Chamahian, A. (2015). Home environments and adaptations in the context of ageing. Ageing \& Society, 35(6), 1278-1303.

Rioux, L., \& Werner, C. (2011). Residential satisfaction among aging people living in place. Journal of Environmental Psychology, 31(2), 158-169.

Sakellariou, D. (2015). Home modifications and ways of living well. Medical Anthropology, 34(5), 456-469.

Sanford, J. A. (2012). Universal design as a rehabilitation strategy: Design for the ages. USA: Springer.

Schwingel, A., Gálvez, P., Linares, D., \& Sebastião, E. (2017). Using a mixed-methods RE-AIM framework to evaluate community health programs for older Latinas. Journal of Aging and Health, 29(4), 551-593.

Scott, J., MacMillan, K., McGregor, T., \& Reid, S. (2009). Review of care and repair projects. Edinburgh: Scottish Government Social Research.

Scottish Government. (2010). The impact of population ageing on housing in Scotland. Edinburgh: Communities Analytical Services.

Statistical Package for the Social Sciences. (2013). SPSS 22.0 for Windows. Chicago, IL: SPSS.

Stevenson, L., \& Huws, C. (2014). Researching Welsh law: What is unique in wales? Hauser Global. Retrieved June 21, 2016, from http://www.nyulawglobal.org/globalex/Wales1.html.

Tanner, B., Tilse, C., \& De Jonge, D. (2008). Restoring and sustaining home: The impact of home modifications on the meaning of home for older people. Journal of Housing For the Elderly, 22(3), $195-215$.

Trench, A., \& Jeffery, C. (2007). Older people and public policy. The impact of devolution. London: Age Concern England.

Van Hoof, J., Kort, H. S., \& Van Waarde, H. (2009). Housing and care for older adults with dementia: A European perspective. Journal of Housing and the Built Environment, 24(3), 369.

Wane, K. (2016). Housing adaptations (major). Edinburgh: The Information Centre.

Wilson, W. (2013) Disabled facilities grants (England). Retrieved 24 June, 2016, from https://www. researchbriefings.files.parliament.uk/documents/SN03011/SN03011.pdf. 